\title{
The direct renin inhibitor aliskiren improves vascular remodelling in transgenic rats harbouring human renin and angiotensinogen genes
}

\author{
Carmine SAVOIA*, Emanuele ARRABITO*, Rosa PARENTE*, Lidia SADA*, Luca MADARO†, \\ Carmine NICOLETTI†, Luigi ZEZZA*, Alessandro ALONZO*, Speranza RUBATTUキ, Serena MICHELINI*, \\ Dominik N. MULLER $\S$ and Massimo VOLPE* ${ }^{*}$ \\ *Division of Cardiology, Department of Clinical and Molecular Medicine, Sant'Andrea Hospital, Sapienza University of Rome, Rome, Italy \\ †DAHFMO-Unit of Histology and Medical Embryology, Sapienza University of Rome, Rome, Italy \\ †IRCCS Neuromed, Pozzilli, IS, Italy \\ §Max-Delbruck Center for Molecular Medicine, Berlin, Germany
}

\begin{abstract}
In the present study, we tested the hypothesis that chronic treatment with the direct rennin inhibitor aliskiren improves the remodelling of resistance arteries in dTGR (double-transgenic rats). dTGR (5 weeks) were treated with aliskiren ( $3 \mathrm{mg} / \mathrm{kg}$ of body mass per day) or ramipril ( $1 \mathrm{mg} / \mathrm{kg}$ of body mass per day) for 14 days and compared with age-matched vehicle-treated dTGR. BP (blood pressure) was similarly reduced in both aliskiren-treated and ramipril-treated rats compared with control dTGR $(167 \pm 1$ and $169 \pm 2 \mathrm{mmHg}$ compared with $197 \pm 4 \mathrm{mmHg}$ respectively; $P<0.05)$. The $\mathrm{M} / \mathrm{L}$ (media-to-lumen) ratio assessed on pressurized preparations was equally reduced in aliskiren-treated and ramipril-treated rats compared with controls $(6.3 \pm 0.5$ and $6.4 \pm 0.2 \%$ compared with $9.8 \pm 0.4 \%$ respectively; $P<0.05)$. Endothelium-dependent and -independent relaxations were similar among the groups. L-NAME ( $N^{G}$-nitro-L-arginine methyl ester) significantly reduced acetylcholine-induced dilation in drug-treated dTGR. This effect was significantly more prominent in aliskiren-treated rats. eNOS (endothelial NO synthase) expression showed a 2 -fold increase only in aliskiren-treated dTGR as compared with controls $(P<0.01)$ and ramipril-treated dTGR $(P<0.05)$. Plasma nitrite, as an index of NO production, was significantly increased in dTGR treated with either aliskiren or ramipril compared with controls. Only aliskiren induced a 2-fold increase in plasma nitrite, which was significantly greater than that induced by ramipril $(P<0.05)$. gp9 ${ }^{\text {phox }}$ expression and ROS (reactive oxygen species) production in aorta were significantly and similarly reduced by both drugs. In conclusion, equieffective hypotensive doses of aliskiren or ramipril reduced the $M / L$ ratio of mesenteric arteries and improved oxidative stress in dTGR. However, only aliskiren increased further NO production in the vasculature. Hence, in dTGR, direct renin inhibition induces favourable effects similar to that induced by ACE (angiotensin-converting enzyme) inhibition in improving vascular remodelling through different mechanisms.
\end{abstract}

Key words: nitric oxide, renin inhibition, reactive oxygen species (ROS), small artery, vascular remodelling

\section{INTRODUCTION}

The activation of the RAS (renin-angiotensin system) is a key factor in the pathophysiology and development of hypertension, and it is responsible in part for the hypertension-related functional and structural alterations in the cardiovascular system [1]. Essential hypertension is characterized by small artery remodelling and increased systemic vascular resistance. These changes might impact regional blood flow regulation and lead to increased risk of end-organ damage. Increased M/L (media-to-lumen) ratio of small resistance arteries is an index of vascular remodelling, which is the most prevalent and possibly the earliest alteration that occurs in the cardiovascular system of hypertensive subjects $[1,2]$, as it may precede the occurrence of endothelial dysfunction [2]. There is evidence that reducing BP (blood pressure) with antihypertensive agents, including ACEis (angiotensin-converting

Abbreviations: ACEi, angiotensin-converting enzyme inhibitor; Angll, angiotensin II; ARB, AT 1 (Angll type 1) receptor blocker; BP, blood pressure; CSA, cross-sectional area; DHE, dihydroethidium; dTGR, double-transgenic rats; eNOS, endothelial NO synthase; L-NAME, $N^{G}$-nitro-L-arginine methyl ester; M/L, media-to-lumen; NOS, NO synthase; PRA, plasma renin activity; PSS, physiological salt solution; RAS, renin-angiotensin system; ROS, reactive oxygen species; SBP, systolic blood pressure; SNP, sodium nitroprusside.

Correspondence: Professor Carmine Savoia (email savoiac@yahoo.it). 
enzyme inhibitors) and ARBs $\left\{\mathrm{AT}_{1}\right.$ [AngII (angiotensin II) type 1] receptor blockers $\}$, improves cardiovascular outcomes [3]. There is also evidence that RAS antagonists have a beneficial effect on target organ damage independently of BP reduction $[1,4,5]$. However, RAS blockade with ACEis or ARBs does not ensure sufficient control of cardiovascular events [6]. Moreover, optimized RAS suppression is difficult to achieve partly for the 'escape phenomenon' as well as because ACEis and ARBs activate compensatory feedback mechanisms that result in renin release and increased PRA (plasma renin activity) [7,8]. In contrast, the inhibition of renin, the rate-limiting step in the RAS cascade, offsets active renin and prevents the formation of both AngI (angiotensin I) and AngII [9]. Aliskiren is the first of newer agents that inhibits renin [10], it is a potent and specific inhibitor of human renin, which leads to dose-dependent reduction in PRA and AngII levels [10]. In experimental and clinical studies aliskiren has demonstrated antihypertensive efficacy comparable with or even superior to that of other classes of antihypertensive drugs, including ACEis and ARBs [10,11].

Furthermore, aliskiren has also been shown to induce cardiorenal protection in experimental models of hypertension such as the hypertensive dTGR (double-transgenic rat), harbouring human renin and angiotensinogen genes [12]. Whether aliskiren ameliorates hypertension-related functional and structural alterations of small arteries remains to be investigated. We tested the hypothesis that chronic treatment with aliskiren improves vascular remodelling in small arteries from dTGR.

\section{MATERIALS AND METHODS}

\section{Animals}

A total of 18 male dTGR (Harlan) harbouring genes for human renin and angiotensinogen, 5 weeks of age, were included in the study. All procedures were conducted in accordance with the guidelines for the experimental use of animals of the University of Rome 'La Sapienza,' where the studies were carried out. Rats were housed under conditions of constant humidity and temperature and subjected to 12-h light/dark cycles. The rats were distributed into three groups of six rats each. A group was implanted subcutaneously with osmotic minipumps (Alzet) infusing the selective renin inhibitor aliskiren ( $3 \mathrm{mg} / \mathrm{kg}$ of body mass per day) for 14 days. A second group was treated with the ACEi ramipril $(10 \mathrm{mg} / \mathrm{kg}$ of body mass per day) in drinking water for 14 days. Treated rats were compared with age-matched control rats receiving vehicle. SBP (systolic BP) was measured by tail-cuff methodology (model BP-2000; Visitech Systems), where the average of three pressure readings was obtained. Thereafter the mice were killed. The serum was collected for further analysis. Aorta was dissected, rinsed in ice-cold PSS (physiological salt solution; $120 \mathrm{mmol} / 1 \mathrm{NaCl}, 25 \mathrm{mmol} / 1 \mathrm{NaHCO}_{3}, 4.7 \mathrm{mmol} / \mathrm{l} \mathrm{KCl}$, $1.18 \mathrm{mmol} / 1 \mathrm{KH}_{2} \mathrm{PO}_{4}, 1.18 \mathrm{mmol} / 1 \mathrm{MgSO}_{4}, 2.5 \mathrm{mmol} / 1 \mathrm{CaCl}_{2}$, $0.026 \mathrm{mmol} / 1$ EDTA and $5.5 \mathrm{mmol} / 1$ glucose, $\mathrm{pH} 7.4$ ) and divided in two segments. One segment ( $5 \mathrm{~mm}$ in length) was placed in OCT and then frozen as described previously $[13,14]$. The second segment was frozen for protein extraction.

\section{Preparation and study of small arteries}

Third-order superior mesenteric arteries ( $\sim 2 \mathrm{~mm}$ in length) were dissected and placed in ice-cold PSS. The arteries were mounted on two glass micro-cannulae in a pressurized myograph chamber. Luminal pressure was set to $45 \mathrm{mmHg}$ with a servo-controlled pump [13]. Vessels were then equilibrated for $1 \mathrm{~h}$ with PSS that was bubbled with $95 \%$ air and $5 \% \mathrm{CO}_{2}$ to give a $\mathrm{pH}$ of 7.4 , and were heated to $37^{\circ} \mathrm{C}$. Endothelium-dependent and -independent relaxations were assessed by measuring the dilatory responses to cumulative doses of acetylcholine $\left(10^{-9}-10^{-4} \mathrm{~mol} / \mathrm{l}\right)$ and SNP (sodium nitroprusside) $\left(10^{-8}-10^{-3} \mathrm{~mol} / \mathrm{l}\right)$ respectively, in vessels precontracted with adrenaline $\left(10^{-5} \mathrm{~mol} / \mathrm{l}\right)$. To evaluate $\mathrm{NO}$ availability, the concentration-response curve to acetylcholine was determined before and after 30-min pre-incubation with the NOS (NO synthase) inhibitor L-NAME $\left(N^{\mathrm{G}}\right.$-nitro-L-arginine methyl ester; $\left.10^{-4} \mathrm{~mol} / \mathrm{l}\right)$. The media and lumen dimensions were measured with the intraluminal pressure maintained at 45 $\mathrm{mmHg}$, in vessels deactivated by perfusion with $\mathrm{Ca}^{2+}$-free PSS containing $10 \mathrm{mmol} / 1$ EGTA for $30 \mathrm{~min}$, as described previously [15].

\section{Protein extraction and Western blot analysis}

Total protein from aorta cleaned from the connective tissue was extracted from frozen tissues as described previously [13]. Protein (30 $\mu \mathrm{g}$ ) was separated by electrophoresis on a $10 \%$ polyacrylamide gel and transferred on to a PVDF membrane. Non-specific binding sites were blocked with $5 \%(\mathrm{w} / \mathrm{v})$ non-fat dried skimmed milk powder in Tris-buffered saline solution with $0.1 \%$ Tween 20 for $1 \mathrm{~h}$ at $24^{\circ} \mathrm{C}$. Membranes were then incubated overnight with the following antibodies: anti-eNOS (endothelial NOS) (1:200 dilution at $4{ }^{\circ} \mathrm{C}$; BD Bioscience) and anti-gp91 phox (1:500 dilution at $4{ }^{\circ} \mathrm{C}$; BD Bioscience). After incubation with secondary antibodies, signals were revealed with chemiluminescence, visualized by autoradiography and quantified densitometrically.

\section{Oxidative fluorescent microtopography}

The oxidative fluorescent dye DHE (dihydroethidium) was used to evaluate in situ production of superoxide as described previously $[13,14]$. Unfixed frozen ring segments of aorta embedded in OCT were cut into $5-10 \mu \mathrm{m}$ thick sections and placed on a glass slide. DHE $\left(2 \times 10^{-6} \mathrm{~mol} / \mathrm{l}\right)$ was topically applied to each tissue section. Slides were incubated in a light-protected humidified chamber at $37^{\circ} \mathrm{C}$ for $30 \mathrm{~min}$ and then coverslips were added $[13,14]$. Images were obtained with a Leica fluorescent microscope. The amount of DHE staining present in the vessel wall was quantified (Northern Eclipse program; EMPIX Imaging) and expressed as a percentage of the DHE fluorescence per total surface area $[13,14]$.

\section{Nitrate/nitrite colorimetric assay}

Plasma nitrite, as an index of NO levels, was evaluated with a colorimetric assay in plasma collected from dTGR. Duplicate samples of plasma $(80 \mu \mathrm{l})$ were incubated with nitrate reductase for $3 \mathrm{~h}$. The plasma NO concentration was determined using the Greiss reaction by measuring combined oxidation products of $\mathrm{NO}$, plasma nitrite $\left[\mathrm{NO}_{2}{ }^{-}\right]$and nitrate $\left[\mathrm{NO}_{3}{ }^{-}\right]$with a colorimetric assay (Cayman). Absorbance was read at $550 \mathrm{~nm}$ using a plate reader (Bio-Rad Laboratories). 


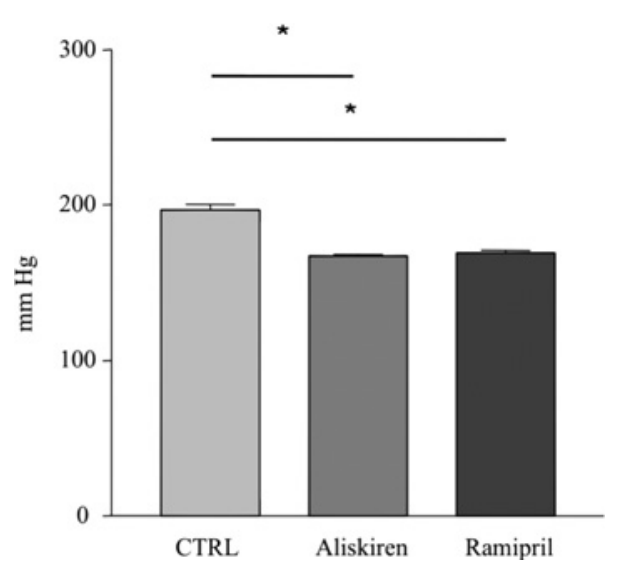

Figure 1 BP of dTGR treated with aliskiren or ramipril CTRL, vehicle-treated dTGR. ${ }^{*} P<0.05$.

\section{Chemicals}

Acetylcholine, SNP, adrenaline and L-NAME were obtained from Sigma Chemicals. The selective renin inhibitor antagonist aliskiren was a gift from Novartis. All the agents were dissolved in saline.

\section{Data analysis}

Results are presented as means \pm S.E.M. and analysed by twoway ANOVA or one-way ANOVA followed by the NewmanKeuls test, for multiple comparisons. A Student's $t$ test was used, where appropriate, for paired observations. $P<0.05$ was considered statistically significant.

\section{RESULTS}

Renin displays high species specificity for its substrate; therefore since dTGR expresses both human renin and angiotensinogen genes, it is a suitable animal model to study the cardiovascular effect of aliskiren, which is an inhibitor of human renin [12]. dTGR were treated with aliskiren or ramipril for 14 days. Vehicle-treated dTGR were used as control. After 2 weeks of treatment SBP was significantly reduced to a comparable degree by both aliskiren and ramipril treatments as compared with vehicle-treated rats $(167 \pm 1$ and $169 \pm 2 \mathrm{mmHg}$ compared with $197 \pm 4 \mathrm{mmHg}$ respectively; $P<0.05$; reduction of -15 and $-14 \% ; P<0.001$; Figure 1).

The $\mathrm{M} / \mathrm{L}$ ratio of mesenteric arteries was equally reduced after 2 weeks in aliskiren-treated and ramipril-treated dTGR compared with control hypertensive dTGR $(6.3 \pm 0.5$ and $6.4 \pm 0.2 \%$ compared with $9.8 \pm .04 \%$ respectively; $P<0.05$; Figure $2 \mathrm{a}$ ). The CSA (cross-sectional area) was slightly, albeit non-significantly, reduced by both pharmacological treatments in mesenteric arteries from dTGR compared with control rats (Figure 2b).

NO bioavailability is traditionally quantified by measuring biologically inactive products of NO (nitrite and nitrate) or acetylcholine-induced vasodilation with/without the NOS inhibitor L-NAME. Acetylcholine-dependent and SNP-dependent relaxations were similar in mesenteric arteries from control and
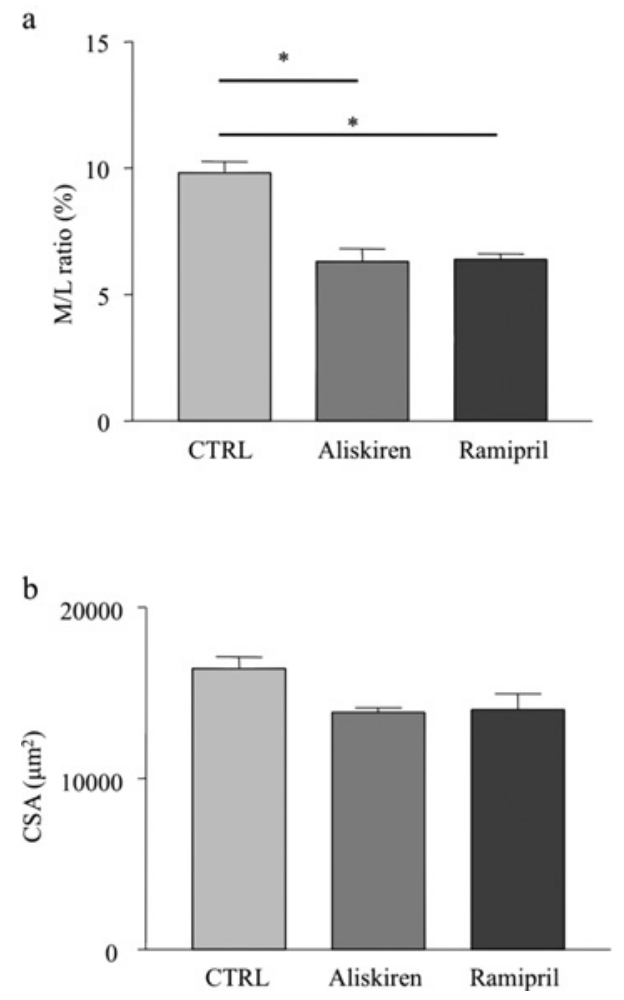

Figure $2 \mathrm{M} / \mathrm{L}$ ratio and CSA of mesenteric arteries from dTGR CTRL, vehicle-treated dTGR. ${ }^{*} P<0.05$.

drugs-treated dTGR (Figures $3 a$ and $3 b$ ). The NOS inhibitor LNAME significantly reduced acetylcholine-induced dilation in aliskiren-treated and ramipril-treated dTGR (Figure 3c). Nevertheless, the inhibitory effect of L-NAME was significantly more prominent in mesenteric arteries from aliskiren-treated rats compared with ramipril-treated rats (Figure 3c) (maximal inhibition $-24.8 \pm 2.9 \%$ compared with $-6.7 \pm 2.9 \%$ respectively; $P<0.01$ ), indicating improvement of eNOS function and an increase in NO synthesis and/or bioavailability in this group. In the control group, L-NAME slightly and not significantly reduced acetylcholine-induced dilation (results not shown).

Plasma nitrite, an index of NO levels, was significantly increased in dTGR treated with either aliskiren or ramipril as compared with control rats $(51.3 \pm 2.1$ and $42.8 \pm 2.1$ arbitrary units compared with $27.6 \pm 1.7$ arbitrary units respectively; $P<0.01$; Figure 4b). Only aliskiren, however, induced a 2-fold increase in plasma nitrite levels compared with the control. This effect was significantly greater than the effect induced by ramipril $(P<0.05$; Figure $4 \mathrm{~b}$ ). Similarly, eNOS expression was increased by more than 2-fold only in aliskiren-treated dTGR as compared with control rats $(P<0.01$; Figure $4 \mathrm{a})$ and ramipril-treated dTGR $(P<0.05$; Figure 4a).

Superoxide generation in aorta was significantly and similarly reduced by both aliskiren and ramipril in dTGR as compared with control rats $(P<0.01$; Figure $5 \mathrm{~b})$. The expression of gp91 ${ }^{\text {phox }}$, the major subunit of NADPH oxidase in the vasculature, was significantly and similarly reduced by both aliskiren and 

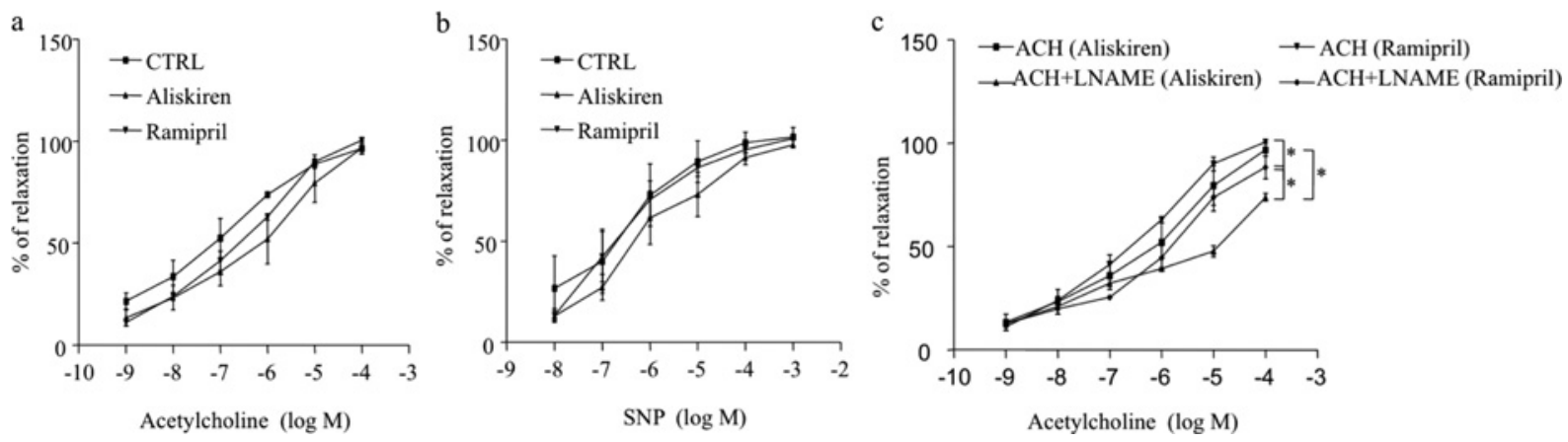

Figure 3 Concentration-response curves to SNP and acetylcholine in the absence or presence of L-NAME in dTGR

(a) Concentration-response curve to acetylcholine and (b) to SNP of noradrenaline-pre-contracted mesenteric arteries from dTGR treated or not with aliskiren or ramipril. (c) Concentration-response curve to acetylcholine (ACH) with the NOS inhibitor L-NAME in aliskiren- and ramipril-treated rats. ${ }^{*} P<0.05$. CTRL, control.
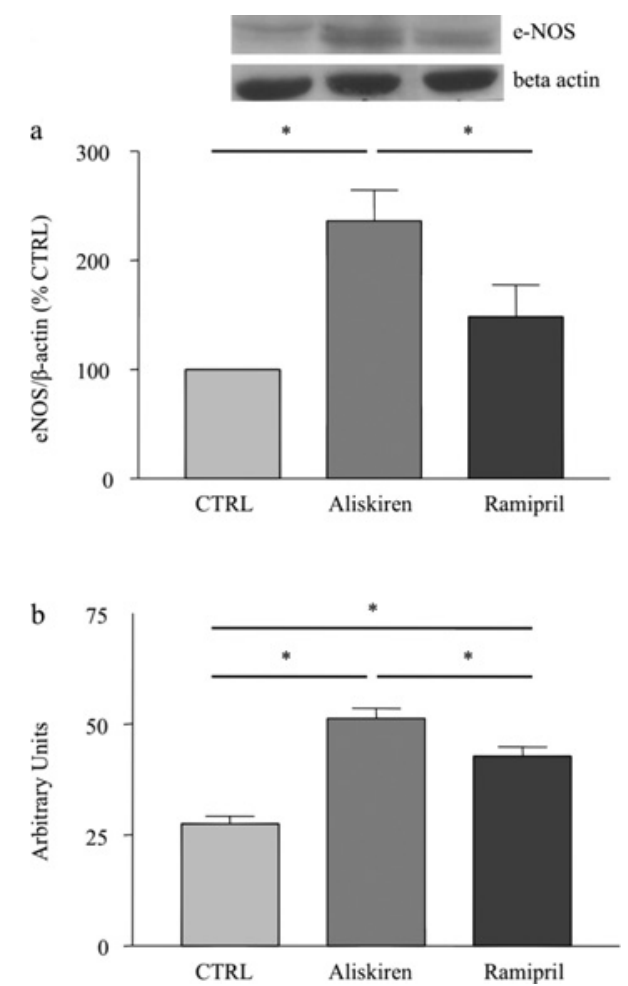

Figure 4 NO bioavailability in dTGR

(a) eNOS expression in aorta of dTGR, the results are presented as percentage of control (CTRL); (b) plasma nitrite production in dTGR. CTRL, vehicle-treated dTGR. $* P<0.05$.

ramipril in aorta of dTGR as compared with control rats $(P<0.05$; Figure 5).

\section{DISCUSSION}

The major findings from the present study are that: (i) equieffective doses of aliskiren and ramipril similarly reduced $\mathrm{M} / \mathrm{L}$ ratio of small arteries of dTGR and similarly reduced ROS (reactive oxy- gen species) production; and (ii) only aliskiren increased eNOS expression and function, improving NO bioavailability in dTGR.

Blood vessels are remodelled in hypertension both structurally and functionally. The changes that occur in their structure and mechanical properties, as well as in vascular function, contribute to BP elevation and complications of hypertension $[1,16]$. Through the increased production of AngII, RAS activation plays a major role in the development of the functional and structural alterations of resistance arteries in hypertensive subjects [1]. Experimental and clinical studies have demonstrated that vascular remodelling of small resistance arteries may be normalized by the treatment with drugs that antagonize the RAS (ACEis and ARBs) [17]. This may be due in part to the reduction of BP as well as to the antagonism of the AngII-mediated effects in the vasculature, including vasoconstriction, cell growth and inflammation $[18,19]$. In particular, ACEis have been shown to improve vascular remodelling in hypertensive patients, independently of BP control [18]. In small arteries from dTGR, the direct renin inhibitor aliskiren improved the $\mathrm{M} / \mathrm{L}$ ratio, an index of vascular remodelling, similarly to the ACEi ramipril. This effect was only partly because of BP reduction. Indeed, both ramipril and aliskiren equally and significantly reduced BP in dTGR as compared with control rats. Nevertheless, the BP values remained in the hypertensive range after 2 weeks of treatment. dTGR is a model of severe hypertension with high renin plasma levels $[12,20]$; therefore it is conceivable that the antihypertensive effect of both aliskiren and ramipril may be partially blunted after 2 weeks of treatment.

The remodelling of small resistance arteries may precede most clinically relevant manifestations of target organ damage in essential hypertension, including endothelial dysfunction $[1,2,4]$. It has been shown, for instance, that almost all hypertensive patients present vascular structural remodelling, although only some exhibit endothelial dysfunction $[1,2,4]$. Endothelial function was similar in dTGR treated either with vehicle or with aliskiren or ramipril. It has been thought that endothelial dysfunction is not present to the same degree in distinct vascular bed [21]. Interestingly, reduced NO release in response to stimuli plays a central role in the pathophysiology of endothelial dysfunction in the conduit arteries, whereas NO in the microcirculation may 


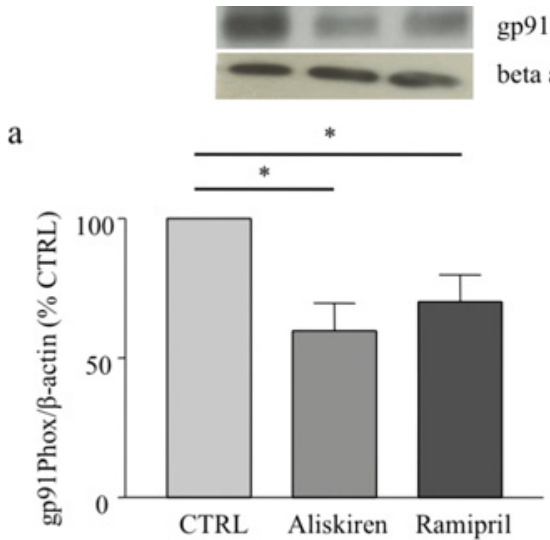

b
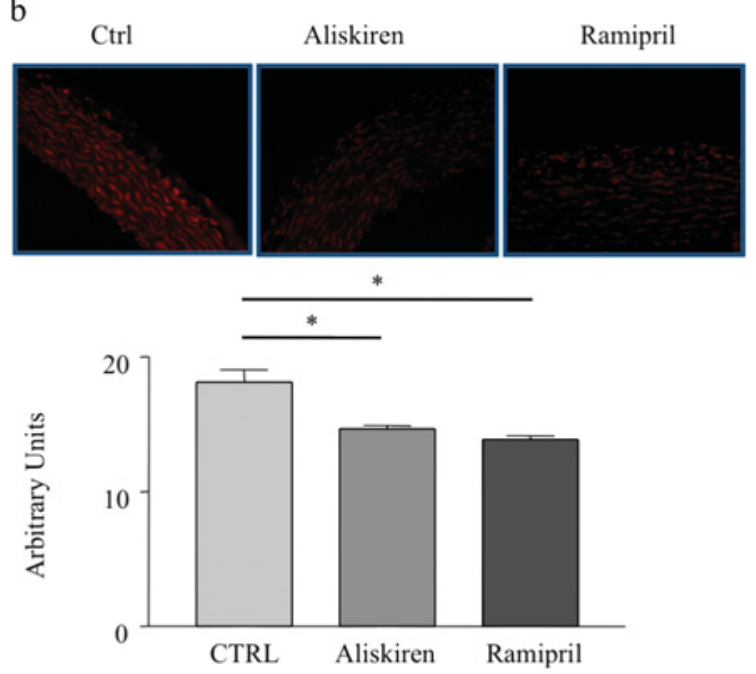

Figure 5 ROS production in dTGR

(a) gp91 ${ }^{\text {phox }}$ expression in aorta of dTGR, the results are presented as percentage of control (CTRL); (b) DHE staining for ROS in aortic rings of dTGR treated or not with aliskiren or ramipril. CTRL, vehicle-treated dTGR. ${ }^{*} P<0.05$.

primarily modulate tissue metabolism [22]. Endothelial function is also regulated by the hyperpolarizing factor, which is modulated by circulating vasoactive substances including acetylcholine and bradykinin. It has been shown that circulating bradykinin may modulate vascular tone and BP in animal models of hypertension with high renin plasma levels [23]. Thus bradykinin may exert a countervailing beneficial effect on endothelial function in experimental models of high renin hypertension. Furthermore, available evidence indicates that ACEis and ARBs do not improve endothelium-dependent vasodilation in the peripheral resistance arteries, although these drug classes are generally effective in reversing vascular alterations in essential hypertension [24-27].

Hypertension-induced vascular remodelling is associated with enhanced, proinflammatory response, cell growth and fibrosis in the vascular wall $[28,29]$. AngII may promote vascular fibrosis and remodelling via several mechanisms, including the inhibition of eNOS activity [27]. Essential hypertension is characterized by the reduction of eNOS activity [20,27,30]. Data from clinical and experimental studies indicate that drugs that enhance eNOS activity play a protective role in the cardiovascular system through the increased NO production, [31,32]. NO plays an anti-inflammatory role by counteracting oxidative stress $[33,34]$ and thus it may contribute to the improvement of cardiovascular remodelling and endothelial function. Interestingly, ramipril and alsikiren increased plasma nitrite in dTGR; however, only aliskiren increased eNOS expression and function and therefore NO production. Thus aliskiren further enhanced NO bioavailability in dTGR. This may contribute to the favourable effect on vascular remodelling. Consistent with this, it has been shown that aliskiren improved the impaired NO bioavailability by increasing plasma NO concentrations in WHHL (Watanabe heritable hyperlipidaemic) rabbits, a model of atherosclerosis [35]. Moreover, aliskiren increased NO availability in the forearm resistance arterioles of hypertensive patients [36].

Vascular inflammation and remodelling induced by neurohormonal systems including the RAS may involve the activation of intracellular signalling related to increased ROS production [37]. In particular, oxidative stress is both a cause and a consequence of hypertension and is a multisystem phenomenon $[1,37]$. It promotes vascular remodelling, reduces NO bioavailability and may amplify BP elevation in the presence of other pro-hypertensive factors. A major source of cardiovascular ROS is the non-phagocytic NADPH oxidase, which is a multimeric enzyme [36]. gp91 $91^{\text {phox }}$ is the major subunit of this enzyme. ACEis and ARBs have demonstrated beneficial cardiovascular effects through the reduction of ROS generation in experimental models as well as in humans [37]. Similarly to ramipril, aliskiren reduced ROS production and gp9 $91^{\text {phox }}$ expression in aorta of dTGR. Hence the direct renin inhibitor aliskiren compares favourably with the ACEi ramipril in reducing ROS production in the vasculature of this model of hypertension with the high plasma renin level. Consistent with our data, aliskiren was also able to reduce NADPHoxidase-induced ROS production in $d b / d b$ mice [38] and in the transgenic Ren2 Rats [39]. Moreover, it has been shown that aliskiren may exert cardiovascular and renal protective effects in different gene-manipulated mice [40-43]. However, owing to the high species specificity of renin for its substrate the dosage of aliskiren used in these animal models were higher as compared with the dosage used in the present study.

The increase of ROS production and the reduction of NO bioavailability may contribute to the hypertension-induced cardiovascular damage. In dTGR, both aliskiren and ramipril reduced ROS production; only aliskiren, however, improved NO biosynthesis, which may contribute to increasing further the NO bioavailability in dTGR. Thus it is conceivable that aliskiren and ramipril may contribute to vascular protection through different mechanisms, beyond BP reduction.

\section{CLINICAL PERSPECTIVES}

- Aliskiren represents an antihypertensive agent with a new mechanism based on the inhibition of a catalytic activity of the renin enzyme, which prevents the activation of the RAS cascade. 
- In the present study, we have shown that, in dTGR harbouring genes for human renin and angiotensinogen, direct renin inhibition induces favourable effects similar to that induced by ACE inhibition in improving vascular remodelling independent of the degree of BP reduction. Thus cardiovascular protective effects appear to be comparable with those of the well-studied ACEis.

- The increased vascular NO bioavailability may contribute to a protective action on vessels, which needs to be better characterized in further studies.

\section{AUTHOR CONTRIBUTION \\ Carmine Savoia conceived and designed the research, handled funding, analysed and interpreted the data, performed the stat- istical analysis, wrote and revised the paper; Emanuele Arrabito, Lidia Sada and Luigi Zezza contributed to the collecting of tissue samples and performed the study on small arteries; Luca Madaro performed oxidative fluorescent microtopography and colorimetric assay; Alessandro Alonzo contributed to performing the studies on animals and on small arteries; Rosa Parente, Serena Michelini per- formed protein extraction and immunoblotting; Carmine Nicoletti performed studies on animals; Speranza Rubattu contributed to re- vision of the paper; Domink Muller supplied the transgenic animals and made critical revisions of the paper; Massimo Volpe handled funding and made critical revisions of the paper.}

\section{FUNDING}

This work was supported by Novartis Pharma.

\section{REFERENCES}

1 Savoia, C., Burger, D., Nishigaki, N., Montezano, A. and Touyz, R. M. (2011) Angiotensin II and the vascular phenotype in hypertension. Expert Rev. Mol. Med. 13, e11

2 Park, J. B. and Schiffrin, E. L. (2001) Small artery remodeling is the most prevalent (earliest?) form of target organ damage in mild essential hypertension. J. Hypertens. 19, 921-930

3 Böhm, M., Baumhäkel, M., Mahfoud, F. and Werner, C. (2010) From evidence to rationale: cardiovascular protection by angiotensin II receptor blockers compared with angiotensin-converting enzyme inhibitors. Cardiology 117, 163-173

4 Park, J. B. and Schiffrin, E. L. (2000) Effects of antihypertensive therapy on hypertensive vascular disease. Curr. Hypertens. Rep. 2, 280-288

5 Bakris, G. (2010) Are there effects of renin-angiotensin system antagonists beyond blood pressure control? Am. J. Cardiol. 105, 21A-29A

6 Turnbull, F., Neal, B., Algert, C., Chalmers, J., Chapman, N., Cutler, J., Woodward, M. and MacMahon, S. (2005) Blood pressure lowering treatment trialists' collaboration. Effects of different blood pressure-lowering regimens on major cardiovascular events in individuals with and without diabetes mellitus: results of prospectively designed overviews of randomized trials. Arch. Intern. Med. 165, 1410-1419
7 Goldberg, M. R., Bradstreet, T. E., McWillams, E. J., Tanaka, W. K., Lipert, S., Bjornsson, T. D., Waldman, S. A., Osborne, B., Pivadori, L., Lewis, G. et al. (1995) Biochemical effects of Iosartan, a nonpeptide angiotensin II receptor antagonist, on the renin-angiotensin-aldosterone system in hypertensive patients. Hypertension 25, 37-46

8 Hollenberg, N. K., Fisher, N. D. and Price, D. A. (1998) Pathways for angiotensin II generation in intact human tissue: evidence from comparative pharmacological interruption of the renin system. Hypertension 32, 387-392

9 Wood, J. M., Cumin, F. and Maibaum, J. (1994) Pathways of renin inhibitors and their application to the treatment of hypertension. Pharmacol. Ther. 61, 325-344

10 Volpe, M., Pontremoli, R. and Borghi, C. (2011) Direct renin inhibition: from pharmacological innovation to novel therapeutic opportunities. High Blood Press. Cardiovasc. Prev. 18, 93-105

11 Nussberger, J., Wuezner, G., Jensen, C. and Brunner, H. R. (2002) Angiotensin II suppression in humans by the orally active renin inhibitor Aliskiren (SPP100): comparison with enalapril. Hypertension 39, E1-E8

12 Pilz, B., Shagdarsuren, E., Wellner, M., Fiebeler, A., Dechend, R., Gratze, P., Meiners, S., Feldman, D. L., Webb, R. L., Garrelds, I. M. et al. (2005) Aliskiren, a human renin inhibitor, ameliorates cardiac and renal damage in double-transgenic rats. Hypertension 46, 569-576

13 Savoia, C., Ebrahimian, T., Lemarié, C. A., Paradis, P., Iglarz, M., Amiri, F., Javeshgani, D. and Schiffrin, E. L. (2010) Countervailing vascular effects of rosiglitazone in high cardiovascular risk mice: role of oxidative stress and PRMT-1. Clin. Sci. 118, 583-592

14 Miller, F. J. Jr., Gutterman, D. D., Rios, C. D., Heistad, D. D. and Davidson, B. L. (1998) Superoxide production in vascular smooth muscle contributes to oxidative stress and impaired relaxation in atherosclerosis. Circ. Res. 82, 1298-1305

15 Savoia, C., Touyz, R. M., Endemann, D. H., Pu, Q., Ko, E. A., De Ciuceis, C. and Schiffrin, E. L. (2006) Angiotensin receptor blocker added to previous antihypertensive agents on arteries of diabetic hypertensive patients. Hypertension 48, 271-277

16 Schiffrin, E. L. (2004) Remodeling of resistance arteries inessential hypertension and effects of antihypertensive treatment. Am. J. Hypertens. 17, 1192-1200

17 Agabiti-Rosei, E., Heagerty, A. M. and Rizzoni, D. (2009) Effects of antihypertensive treatment on small artery remodelling. J. Hypertens. 27, 1107-1114

18 Sharifi, A. M., Li, J. S., Endemann, D. and Schiffrin, E. L. (1998) Effects of enalapril and amlodipine on small-artery structure and composition, and on endothelial dysfunction in spontaneously hypertensive rats. J. Hypertens. 16, 457-466

19 Li, J. S., Sharifi, A. M. and Schiffrin, E. L. (1997) Effect of AT1 angiotensin-receptor blockade on structure and function of small arteries in SHR. J. Cardiovasc. Pharmacol. 30, 75-83

20 Touyz, R. M. (2005) Molecular and cellular mechanisms in vascular injury in hypertension: role of angiotensin II. Curr. Opin. Nephrol. Hypertens. 14, 125-131

21 Flammer, A. J., Anderson, T., Celermajer, D. S., Creager, M. A. Deanfield, J., Ganz, P., Hamburg, N. M., Lüscher, T. F., Shechter, M., Taddei, S. et al. (2012) The assessment of endothelial function: from research into clinical practice. Circulation 126, 753-767

22 Trochu, J. N., Bouhour, J. B., Kaley, G. and Hintze, T. H. (2008) Role of endothelium derived nitric oxide in the regulation of cardiac oxygen metabolism: implications in health and disease. Circ. Res. 87, 1108-1117

23 Waeber, B., Aubert, J. F., Nussberger, J., Vavrek, R., Stewart, J. M. and Brunner, H. R. (1987) Influence of bradykinin on blood pressure regulation of spontaneously hypertensive rats maintained on different sodium intakes. Clin. Exp. Pharmacol. Physiol. 14, 659-664

24 Creager, M. A. and Roddy, M. A. (1994) Effect of captopril and enalapril on endothelial function in hypertensive patients. Hypertension 24, 499-505 
25 Kiowski, W., Linder, L., Nuesch, R. and Martina, B. (1996) Effects of cilazapril on vascular structure and function in essential hypertension. Hypertension 273 Pt 1, 371-376

26 Klingbeil, A. U., John, S., Schneider, M. P., Jacobi, J., Handrock, R. and Schmieder, R. E. (2003) Effect of AT1 receptor blockade on endothelial function in essential hypertension. Am. J. Hypertens. 16, 123-128

27 Cai, H. and Harrison, D. G. (2000) Endothelial dysfunction in cardiovascular diseases: the role of oxidant stress. Circ. Res. 87, 840-844

28 Schiffrin, E. L. (2004) Remodeling of resistance arteries inessential hypertension and effects of antihypertensive treatment. Am. J. Hypertens. 17, 1192-1200

29 Mulvany, M. J. (2002) Small artery remodeling in hypertension. Curr. Hypertens. Rep. 4, 49-55

30 Taddei, S., Virdis, A., Mattei, P., Ghiadoni, L., Sudano, I. and Salvetti, A. (1996) Defective L-arginine-nitric oxide pathway in offspring of essential hypertensive patients. Circulation 94, 1298-1303

31 Forstermann, U. and Munzel, T. (2006) Endothelial nitric oxide synthase in vascular disease: from marvel to menace. Circulation 113, 1708-1714

32 Schmerbach, K., Pfab, T., Zhao, Y., Culman, J., Mueller, S., Villringer, A., Muller, D. N., Hocher, B., Unger, T. and Thoene-Reineke, C. (2010) Effects of aliskiren on stroke in rats expressing human renin and angiotensinogen genes. PloS ONE 5, e15052

33 Giordano, F. J. (2005) Oxygen, oxidative stress, hypoxia, and heart failure. J. Clin. Invest. 115, 500-508

34 Gamboa, A., Shibao, C., Diedrich, A., Choi, L., Pohar, B., Jordan, J., Paranjape, S., Farley, G. and Biaggioni, I. (2007) Contribution of endothelial nitric oxide to blood pressure in humans. Hypertension 49, 170-177

35 Imanishi, T., Tsujioka, H., Ikejima, H., Kuroi, A., Takarada, S., Kitabata, H., Tanimoto, T., Muragaki, Y., Mochizuki, S., Goto, M. et al. (2008) Renin inhibitor aliskiren improves impaired nitric oxide bioavailability and protects against atherosclerotic changes. Hypertension 52, 563-572
36 Virdis, A., Ghiadoni, L., Qasem, A. A., Lorenzini, G., Duranti, E., Cartoni, G., Bruno, R. M., Bernini, G. and Taddei, S. (2012) Effect of aliskiren treatment on endothelium-dependent vasodilation and aortic stiffness in essential hypertensive patients. Eur. Heart J. 33, 1530-1538

37 Touyz, R. M. and Briones, A. M. (2011) Reactive oxygen species and vascular biology: implications in human hypertension. Hypertens. Res. 34, 5-14

38 Dong, Y. F., Liu, L., Kataoka, K., Nakamura, T., Fukuda, M., Tokutomi, Y., Nako, H., Ogawa, H. and Kim-Mitsuyama, S. (2010) Aliskiren prevents cardiovascular complications and pancreatic injury in a mouse model of obesity and type 2 diabetes. Diabetologia 53, 180-191

39 Habibi, J., Whaley-Connell, A., Hayden, M. R., DeMarco, V. G., Schneider, R., Sowers, S. D., Karuparthi, P., Ferrario, C. M. and Sowers, J. R. (2008) Renin inhibition attenuates insulin resistance, oxidative stress, and pancreatic remodeling in the transgenic Ren2 rat. Endocrinology 149 5643-5653

40 Yamamoto, E., Kataoka, K., Dong, Y. F., Nakamura, T., Fukuda, M., Tokutomi, Y., Matsuba, S., Nako, H., Nakagata, N., Kaneko, T. et al. (2009) Aliskiren enhances the protective effects of valsartan against cardiovascular and renal injury in endothelial nitric oxide synthase-deficient mice. Hypertension $\mathbf{5 4}$, 633-638

41 Lu, H., Balakrishnan, A., Howatt, D. A., Wu, C., Charnigo, R., Liau, G., Cassis, L. A. and Daugherty, A. (2012) Comparative effects of different modes of renin-angiotensin system inhibition on hypercholesterolaemia-induced atherosclerosis. Br. J. Pharmacol. 165, 2000-2008

42 Kang, Y. S., Lee, M. H., Song, H. K., Hyun, Y. Y., Cha, J. J., Ko, G. J., Kim, S. H., Lee, J. E., Han, J. Y. and Cha, D. R. (2011) Aliskiren improves insulin resistance and ameliorates diabetic vascular complications in $\mathrm{db} / \mathrm{db}$ mice. Nephrol. Dial. Transplant. 26, 1194-1204

43 Leibovitz, E. and Schiffrin, E. L. (2007) Novel drugs targeting hypertension: renin inhibitors and beyond. J. Cardiovasc. Pharmacol. 50, 3-8 